\title{
Dens of inactivity
}

$\mathrm{F}$ or many cubicle dwellers, the daily dose of physical activity consists of little more than tapping a keyboard, clicking a mouse and occasionally moving a coffee-filled mug from desktop to maw. Calories burned: not many. Although workers who sweat while earning a paycheque still exist, technology has, for the most part, transformed the workplace into a den of inactivity.

Same goes for the home. Today, entertainment generally consists of looking at a screen, be it the giant plasma in the living room on which you watch American Idol, the iPhone display on which you play Angry Birds, or the computer monitor on which you watch YouTube videos of water-skiing squirrels. According to health experts, many humans would be wise to follow those squirrels' lead and get off their tails, so to speak, and get more exercise.

That would benefit nearly a third of the world's population, according to a new report from the World Health Organization (WHO). Their physical inactivity contributes to more than 670000 deaths of people under the age of 60 and can lead to heart disease, diabetes and other noncommunicable diseases, says the report, Global Recommendations on Physical Activity for Health (http://whq libdoc.who.int/publications/2010/97892 41599979_eng.pdf). Physical inactivity is the fourth-leading risk factor for all deaths, the report states, and is associated with 2.6 million deaths in low- and middle-income countries and 3.2 million deaths overall.

"That's quite a large figure, and it's growing larger as we speak," says Godfrey Xuereb, team leader for population-based prevention in the WHO's Surveillance and Population-based Prevention Unit. "When we look at recommended physical activity levels, in many countries they are not being achieved."

Physical activity can also reduce the risk of breast and colon cancers, according to the report, which was released on

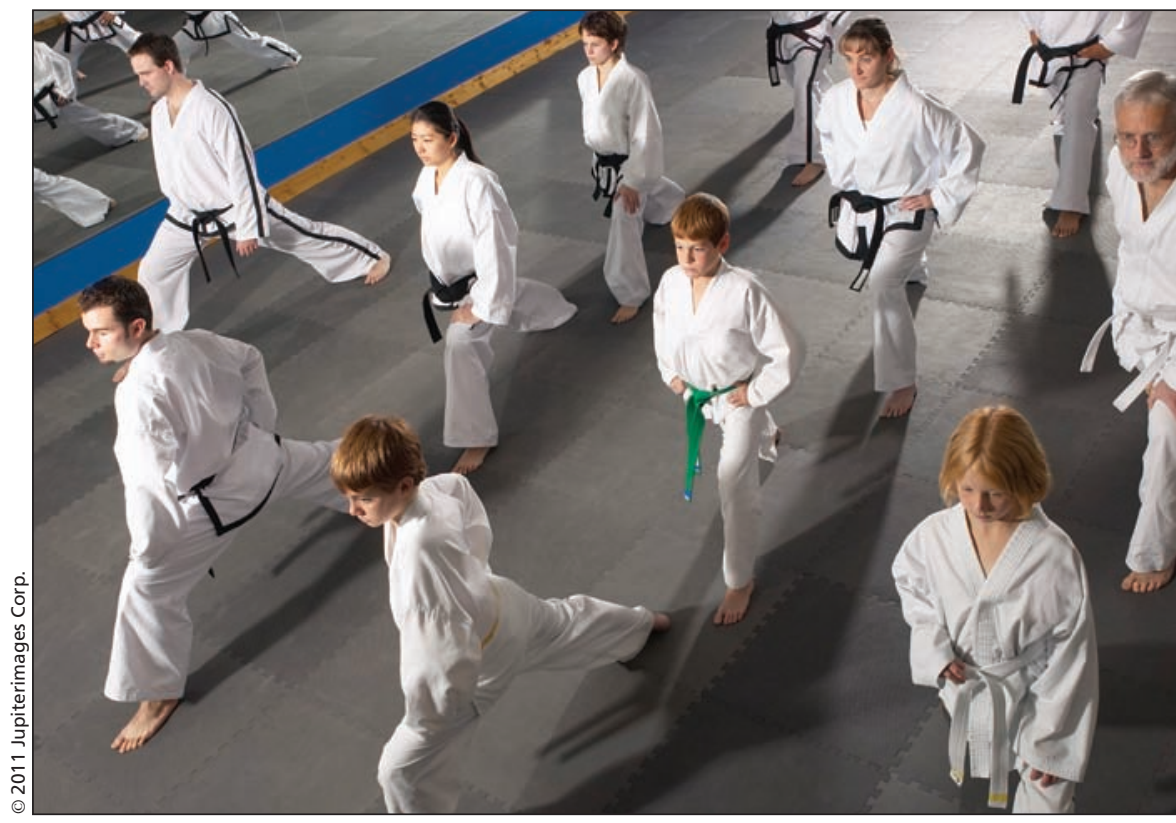

Roughly 150 minutes of moderately intensive aerobic activity each week could reduce the risk of acquiring diabetes, heart disease and breast or colon cancer, according to the World Health Organization.

World Cancer Day 2011 (Feb. 4). In 2008, these two cancers killed more than a million people. For people aged 18 and over, the report states, only 150 minutes of moderately intensive aerobic activity a week could reduce the risk of acquiring breast or colon cancer, as well as diabetes and heart disease.

"The main focus of these global recommendations is to look at the prevention of noncommunicable diseases through physical activity," says Xuereb.

The inclusion of cancer prevention as a benefit of physical activity in a set of guidelines is a welcome change, says Christine Friedenreich, leader of population health research for Alberta Health Services-Cancer Care and a leading researcher on the effects of physical activity on cancer prevention.

"Most physical activity guidelines are based on preventing cardiovascular diseases or diabetes, but recommending physical activity to reduce the risk of cancer, and on the post-diagnosis side for rehabilitation, that is a burgeoning area of research," says Friedenreich. "Adding cancer to the list is extremely important. There are few modifiable risk factors that reduce the chances of getting cancer. Quitting smoking is the obvious one, but changing your physical activity level and diet is a more subtle message."

Still, it may be a bit premature to recommend a specific amount of time of physical activity as a prescription for preventing cancer, says Friedenreich. The science just isn't there yet. "That's what I'm working on now, as we speak," she says. "What is the optimal level of physical activity for cancer prevention?" The answer to that question, she adds, remains to be seen.

Of course, it is one thing to inform people of the health benefits of physical activity; it is quite another to compel widespread changes in behaviour so those benefits become reality. "These recommendations are only the first step. This is the science behind the evidence," says Xuereb. "Next we are going to work with countries, and each setting is different, on how to implement these recommendations."

To encourage a society to become 
more active, Xuereb says, will require enormous effort. It will require cities to create open spaces for people to walk in and sidewalks on which they can commute to work. It will require schools to encourage students to be more active. It will require governments to ensure streets and playgrounds are safe for chil- dren. It will require businesses to create places for people to park their bicycles. It will require urban centres to accommodate the limited mobility of its senior citizens, among other changes.

"Urban development has to change so that we are not cutting communities in half. People who once walked to school now have a four- or five-lane highway to cross and that makes them use mechanical transport," says Xuereb. "This is more than an all-of-government initiative. It takes a whole-of-society initiative." - Roger Collier, CMAJ

CMAJ 2011. DOI:10.1503/cmaj.109-3808 